\title{
Differential Expression of Fos and Zif268 in the Nigrostriatal System After Methamphetamine Administration in a Rat Model of Parkinson's Disease
}

\author{
YASUSHI ISHIDA, ${ }^{1 *}$ KEIICHI KAWAI, ${ }^{2}$ YASUHIRO MAGATA, ${ }^{3}$ KOSUKE EBIHARA, ${ }^{1}$ \\ RYUICHIRO TAKEDA, ${ }^{1}$ HIROSHI ABE, ${ }^{1}$ MITSUYOSHI YOSHIMOTO,${ }^{2}$ HIROYUKI HASHIGUCHI, ${ }^{1}$ \\ KEI ODAGIRI, ${ }^{1}$ HISAE MATSUO,${ }^{1}$ AND TOSHIKAZU NISHIMORI ${ }^{4}$ \\ ${ }^{1}$ Department of Psychiatry, Faculty of Medicine, University of Miyazaki, Kiyotake-cho, Miyazaki-gun, \\ Miyazaki 889-1692, Japan \\ ${ }^{2}$ Department of Quantum Medical Technology, Division of Health Sciences, Graduate School of Medical Sciences, \\ Kanazawa University, Kanazawa 920-0942, Japan \\ ${ }^{3}$ Laboratory of Genome Bio-Photonics, Photon Medical Research Center, Hamamatsu University School of Medicine, \\ Hamamatsu 431-3192, Japan \\ ${ }^{4}$ Division of Neurobiology, Faculty of Medicine, University of Miyazaki, Kiyotake-cho, Miyazaki-gun, \\ Miyazaki 889-1692, Japan
}

\begin{abstract}
KEY WORDS 6-hydroxydopamine; immediate-early gene proteins; basal ganglia;
\end{abstract} transplantation

\begin{abstract}
The goal of this study was to examine the topological specificity of methamphetamine-induced activation of the immediate-early gene proteins, Fos and Zif268, in the nigrostriatal system in a unilateral 6-hydroxydopamine (6-OHDA) rat model of Parkinson's disease with or without intrastriatal grafts of fetal ventral mesencephalon. Methamphetamine ( $3 \mathrm{mg} / \mathrm{kg}$, i.p.) induced Fos-like immunoreactivity (FLI) dominantly in the striatum and the globus pallidus (GP) on the intact side as well as in the substantia nigra pars reticulata $(\mathrm{SNr})$ on the lesioned side in the 6OHDA rats. Lower levels of methamphetamine-induced FLI in the striatum and GP on the lesioned side were restored by intrastriatal grafts which could completely suppress the methamphetamine-induced rotation. In the striatum, a similar tendency could be observed between Fos and Zif268 immunoreactivity following methamphetamine. However, sparse immunoreactivity of Zif268 could be detected in the GP and $\mathrm{SNr}$ on both sides in the 6-OHDA rats. Intrastriatal grafts had little influence on Zif268 expression in these two regions. The differential expression of Fos and Zif268 was observed among the three regions of the nigrostriatal system following methamphetamine in the 6-OHDA rats. This may suggest that Fos and Zif268 therefore possess gene-specific and region-specific functions in the basal ganglia nuclei. Synapse 62:920-926, 2008. @ 2008 Wiley-Liss, Inc.
\end{abstract}

\section{INTRODUCTION}

Despite intensive study, the character and the function of immediate-early genes (IEGs) in the central nervous system (CNS) have not yet been elucidated. The induction of cellular IEGs may be a critical signal transduction step in neuronal plasticity induced by neurotransmitters and drugs, with the protein products of IEGs functioning to either activate or repress genes that encode the proteins involved in the differentiated functions of target neurons. The induction of the IEG, c-fos, in the CNS has thus been proposed to be indicative of synaptic activation, and it may also be involved in converting short-term extracellular signals to long-term intracellular responses (Morgan and Curran, 1991; Sheng and Greenberg, 1990).

Zif268 (also known as NGFI-A, Egr-1, and Krox24), and also Fos, are transcription factors that may

\footnotetext{
Contract grant sponsor: Japan Society for the Promotion of Science.

*Correspondence to: Yasushi Ishida, Department of Psychiatry, Faculty of Medicine, University of Miyazaki, 5200 Kihara, Kiyotake-cho, Miyazaki-gun, Miyazaki 889-1692, Japan. E-mail: ishiday@med.miyazaki-u.ac.jp

Received 24 February 2008; Accepted 30 April 2008

DOI 10.1002/syn.20558

Published online in Wiley InterScience (www.interscience.wiley.com).
} 
regulate neuronal and nonneuronal gene expression in the mammalian brain (Dragunow et al., 1989; Morgan and Curran, 1991). The transcriptional activity of the Fos family of molecules is dependent upon them forming heterodimers, using a leucine-zipper motif, with the Jun family of transcription factors (Kerpolla and Curran, 1991), whereas, members of the Krox family of transcription factors bind to DNA using a zinc-finger motif (Lemaire et al., 1988, 1990). Regional difference among five regions [caudate-putamen $(\mathrm{CPu})$, globus pallidus (GP), entopeduncular nucleus, subthalamic nucleus, substantia nigra pars reticulata $(\mathrm{SNr})]$ of the basal ganglia are observed in the basal expression of Zif268, and constitutive expression of Zif268 occurring mainly in the GABAergic neurons in the $\mathrm{CPu}$ may at least in part be maintained by glutamatergic afferents (Ishida et al., 2000).

Various dopaminergic and CNS stimulating drugs such as cocaine, amphetamine, and methamphetamine have been reported to induce (or up-regulate) both the Fos and Zif268 expression in the terminal region of the nigrostriatal dopamine (DA) system, the striatum (Bhat et al., 1992; Hebb and Robertson, 1997; Umino et al., 1995). In rats with a unilateral lesion of the nigrostriatal DA pathway induced by the 6-hydroxydopamine (6-OHDA), systemic administration of an indirect DA agonist such as amphetamine or methamphetamine produces ipsilateral rotational behavior by releasing DA following the stimulation of DA receptors in the intact side of the brain (Ungerstedt, 1971). Methamphetamine-induced rotational behavior is accompanied by the expression of Fos-like immunoreactivity (FLI) in the nigrostriatal components in 6-OHDA rats (Ishida et al., 1998b). This was observed not only in the striatum contralateral to the unilateral 6-OHDA-induced lesion in the nigrostriatal pathway, as reported previously (Abrous et al., 1992; Cenci et al., 1992; Robertson et al., 1989), but also in the SNr ipsilateral to the lesion. The asymmetry in the FLI between the hemispheres following methamphetamine treatment has also been confirmed by other researchers (Hebb and Robertson, 1999; Wirtshafter and Asin, 1999).

The goal of this study was to examine the topological specificity of methamphetamine-induced activation of the IEG proteins, Fos and Zif268 in three regions (medial $\mathrm{CPu}, \mathrm{GP}, \mathrm{SNr}$ ) of the nigrostriatal system in a unilateral 6-OHDA rat model of Parkinson's disease with or without intrastriatal grafts of fetal ventral mesencephalon (VM). There have been few reports concerning amphetamine- or methamphetamineinduced Zif268 expression in basal ganglia of an animal model of Parkinson's disease (Hebb and Robertson, 1997). In particular, the effect of intrastriatal dopaminergic transplants on the IEG expression has not yet been elucidated.

\section{MATERIALS AND METHODS Animals}

Male Wistar rats (Japan SLC, Hamamatsu, Japan), weighing $120-130 \mathrm{~g}$ at the beginning of the experiment, were used. They were housed in a group of 3-4 rats under a $12 \mathrm{~h}$ light/dark cycle with free access to food and water. The experimental protocols used in this study were approved by the ethical committees of animal experimentation at the University of Miyazaki.

\section{6-OHDA lesion and transplantation surgery}

The rats were anesthetized with pentobarbital (50 mg/kg, i.p.), and unilateral lesions of the left medial forebrain bundle (MFB) were made by the injection of $8 \mu \mathrm{g}$ 6-OHDA hydrobromide (Sigma, MA) in $4 \mu \mathrm{l}$ of sterile saline containing $0.01 \%$ ascorbic acid. The stereotaxic coordinates for the lesions were $3.3 \mathrm{~mm}$ rostral to the interaural line, $1.3 \mathrm{~mm}$ left of the midline, and $6.7 \mathrm{~mm}$ ventral to the dural surface. The incisor bar was set $2.4 \mathrm{~mm}$ below the level of the ear bars (König and Klippel, 1963). The 6-OHDA solution was delivered by a microinjection pump at $1 \mu \mathrm{l} / \mathrm{min}$, and the cannula was left in place for $5 \mathrm{~min}$ after the end of injection. In addition to the 6-OHDA-treated rats, twelve age-matched rats were used as sham-lesioned controls for the histological experiments. Sham lesions were created by injecting the same amount $(4 \mu \mathrm{l})$ of saline into the left MFB as described above.

Neural transplantation was performed from fetal VM tissue according to the cell suspension method (Björklund and Dunnett, 1992; Dunnett and Björklund, 1992). Six microliters of the suspension containing $4.8 \times 105$ cells from 15-day-old rat embryos was injected into two sites of the denervated striatum: (1) $\mathrm{AP}=1.0 \mathrm{~mm}$ rostral to the bregma, $\mathrm{L}=$ $2.5 \mathrm{~mm}$ left of midline, $\mathrm{V}=5.0 \mathrm{~mm}$ ventral to the dural surface, and (2) AP $=0.0 \mathrm{~mm}$ caudal to the bregma, $\mathrm{L}=3.2 \mathrm{~mm}$ left of midline, $\mathrm{V}=5.0 \mathrm{~mm}$ ventral to the dural surface (König and Klippel, 1963). All graft suspensions were injected at a rate of $1 \mu \mathrm{l} / \mathrm{min}$, and the syringe was left in place for $5 \mathrm{~min}$ after the end of the injection.

\section{Rotational behavior}

The motor disturbance was assessed by counting the full-rotations per min in a cylindrical container (30-cm diameter) at $10-\mathrm{min}$ intervals for the first $60 \mathrm{~min}$ after methamphetamine ( $3 \mathrm{mg} / \mathrm{kg}$, i.p. $)$ administration (Nishino et al., 1990; Ungerstedt, 1971). Behavioral screening was carried out after 2 weeks recovery, and the animals that turned no less than 7 turns/min on methamphetamine challenge were included in the study. There is an immediate and almost complete destruction of the DA neurons of the 
substantia nigra and of the ventral tegmental area, thus resulting in the near total depletion ( $2 \%$ of normal) of DA in the ipsilateral striatum to the 6-OHDA injections (Ishida et al., 1998a). The rats were tested again for rotational asymmetry at 7 and 15 weeks after the 6-OHDA treatment (at 4 and 12 weeks after transplantation).

\section{Histological procedure}

Methamphetamine treatment and subsequent perfusion of the animals was carried out 4-5 months after the induction of the 6-OHDA lesion. Six agematched control rats were also included in the study in which the rats were treated with an equal volume of saline. Two hours after methamphetamine (3 mg/ $\mathrm{kg}$, i.p.) treatment, the rats were deeply anesthetized with an overdose of pentobarbital and were perfused transcardially first with saline followed by $4 \%$ paraformaldehyde in 0.1 M phosphate buffer (PB; pH 7.4). The brains were removed immediately and postfixed at $4{ }^{\circ} \mathrm{C}$ for $1 \mathrm{~h}$ in the above fixative. After fixation, the samples were immersed at $4{ }^{\circ} \mathrm{C}$ for $1 \mathrm{~h}$ in $0.1 \mathrm{M} \mathrm{PB}$ with $10 \%$ sucrose and cryoprotected at $4{ }^{\circ} \mathrm{C}$ overnight in the same buffer with $30 \%$ sucrose. The brains were subsequently cut on a freezing microtome into $50 \mu \mathrm{m}$ coronal sections for immunohistochemistry. An immunohistochemical examination of Fos or Zif268 expression was performed according to the manufacturer's instructions for use of a streptavidin-biotin system (Histofine SAB-PO(R) kit, Nichirei, Tokyo, Japan). Briefly, biotinylated secondary antibodies were coupled with streptavidin-biotinylated horseradish peroxidase, and the reaction was visualized using diaminobenzidine (DAB) as a chromogen enhanced by cobalt chloride. Between each incubation step, the free-floating sections were thoroughly rinsed with phosphate-buffered saline. The antibodies for c-Fos and Zif268 were rabbit polyclonal antisera (diluted 1:5000 and 1:3000, respectively; Santa Cruz Biotechnology, CA). For each animal and each IEG protein, 3 sections through the $\mathrm{CPu}$ approximately $0.7 \mathrm{~mm}$ rostral to the bregma, 3 sections through the GP $\sim 1.0 \mathrm{~mm}$ caudal to the bregma and 3 sections through the SN $\sim 2.2 \mathrm{~mm}$ rostral to the interaural line were selected for quantitative analysis (König and Klippel, 1963). Fos or Zif268 immunoreactivity in the medial $\mathrm{CPu}, \mathrm{GP}$, and $\mathrm{SNr}$ was quantified by counting the number of cells immunopositive for Fos or Zif268, respectively, in $0.5 \mathrm{~mm} \times 0.5 \mathrm{~mm}\left(0.25 \mathrm{~mm}^{2}\right)$ squares using a $10 \times$ microscope objective. Thereafter, the numbers obtained from the 3 sections in each area (medial $\mathrm{CPu}, \mathrm{GP}$, or $\mathrm{SNr}$ ) were averaged to give the results for each animal and each IEG protein. The data are therefore presented as the number of cells immunopositive for Fos or Zif268 per $0.25 \mathrm{~mm}^{2}$ of striatal, pallidal or nigral tissue (Ishida et al., 1998b).

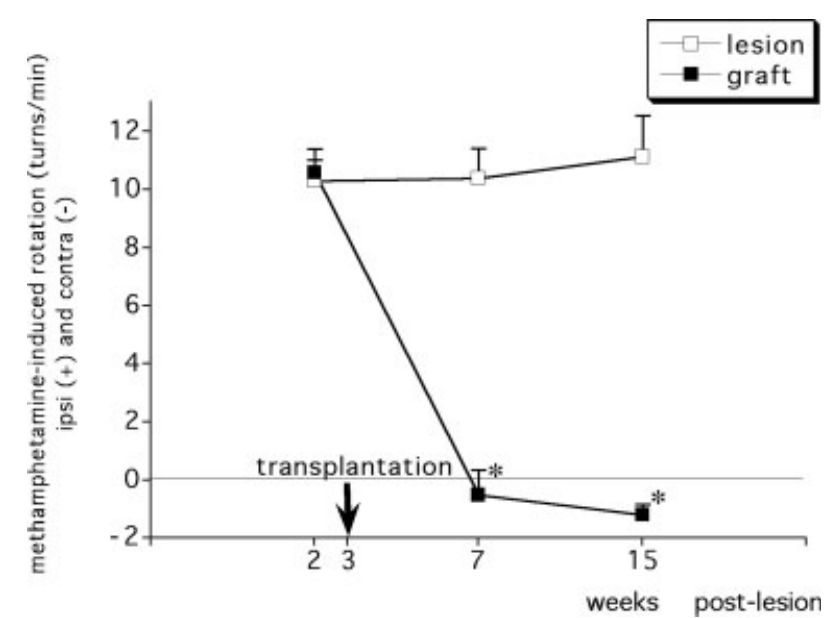

Fig. 1. The mean number of rotations $( \pm$ SEM) per min over a $60 \mathrm{~min}$ test period in response to methamphetamine $(3 \mathrm{mg} / \mathrm{kg}$ i.p. are shown for unilaterally 6-OHDA-lesioned (lesion; $n=12$ ) and the lesion plus grafted rats (graft; $n=6$ ). "ipsi $(+)$ " and "contra $(-)$ " refer to the direction of rotation to side of lesion and transplantation. The decrease in the ipsilateral rotation found in the group receiving fetal VM grafts in comparison to that observed in the lesioned animals was significant at 4 and 12 weeks after transplantation $(* P<0.01$, two way ANOVA with repeated measures followed by Newman-Keuls test).

\section{Statistical analysis}

The data were analyzed by ANOVA followed by post hoc comparisons, when appropriate, using the Newman-Keuls test or the Dunnett's $t$-test. $P$ values $<$ 0.05 were regarded as being statistically significant.

\section{RESULTS Rotational behavior}

Before transplantation, methamphetamine (3 mg/ $\mathrm{kg}$, i.p.) induced strong ipsilateral rotation in 6OHDA-lesioned rats (mean $\pm \mathrm{SEM}=10.4 \pm 0.5$ turns/min). In the lesioned animals ( $n=12)$, methamphetamine-induced rotation continued to be observed 15 weeks following induction of the lesion. This behavior was reversed by the intrastriatal graft in the 4 th week after transplantation ( 7 weeks postlesion), and then continued throughout 12 weeks post-grafting (main effect of groups, $F 1,32=33.75$, $P<0.01$; main effect of time, $F 2,32=21.32, P<$ 0.01 ; groups $\times$ time interaction, $F 2,32=25.59, P<$ 0.01 ). Some of the grafted animals turned away from the grafted side in a contralateral direction $(-0.2 \pm$ 1.2 turns $/ \mathrm{min}$ at 4 weeks and $-1.3 \pm 0.9$ turns $/ \mathrm{min}$ at 12 weeks post-grafting; $n=6$ ), which was considered to be a functional overcompensation in their rotational behavior (Fig. 1).

\section{Fos and Zif268 immunohistochemistry}

In the saline-treated control animals, Fos-positive cells were very sparse in all three regions observed: the medial $\mathrm{CPu}, \mathrm{GP}$, and $\mathrm{SNr}$ (Fig. 3). In contrast, 


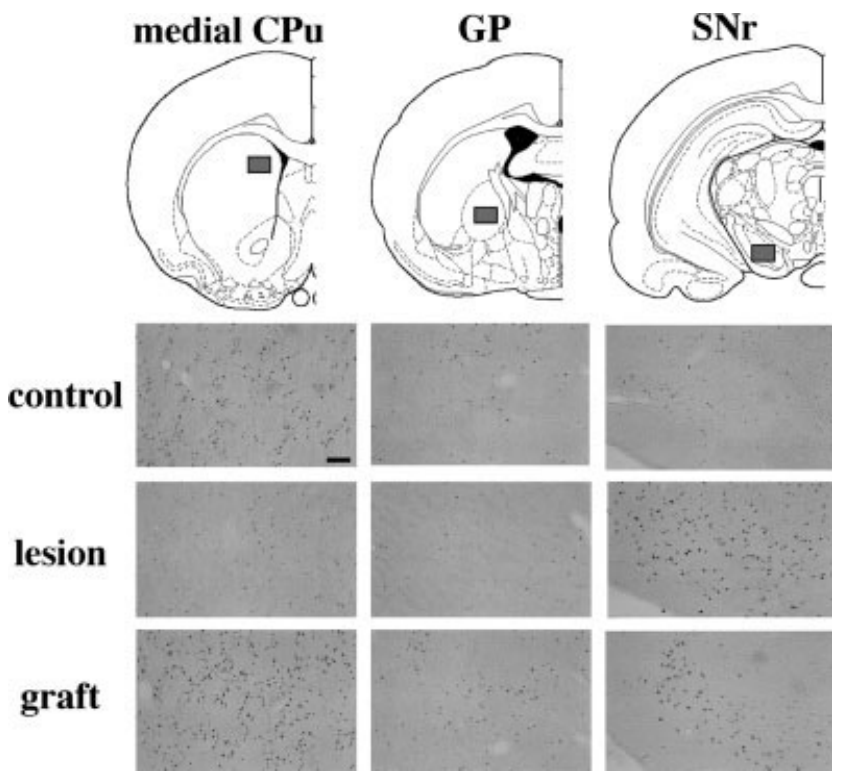

Fig. 2. Fos expression $2 \mathrm{~h}$ after methamphetamine $(3 \mathrm{mg} / \mathrm{kg}$, i.p.) administration in the basal ganglia nuclei of the control, the lesioned and the grafted rats ipsilateral to the lesion/graft (left side). $\mathrm{CPu}$, caudate putamen; GP, globus pallidus; $\mathrm{SNr}$, substantia nigra pars reticulata. The box in the drawing indicates the location of areas where photomicrographs were taken. Scale bar $=100 \mu \mathrm{m}$.

Zif268 was expressed in relatively high levels basally in the medial $\mathrm{CPu}$, but sparse in both the GP and the SNr (Fig. 5).

The administration of methamphetamine to the 6OHDA rats induced Fos expression in the medial $\mathrm{CPu}$ and GP on both sides; the number of Fos-positive cells was smaller on the lesioned side than on the intact side especially in the GP (Fig. 3). In contrast, the number of Fos-positive cells in the $\mathrm{SNr}$ in the 6OHDA rats was greater on the lesioned side than on the intact side. In the grafted rats, methamphetamine-induced FLI in the medial $\mathrm{CPu}$ on the lesion-grafted side was higher than that in the normal striatum of control animals. The decreased levels of methamphetamine-induced FLI in the GP on the lesioned side were restored by the intrastriatal grafts. However, the hyperexpression of FLI in the SNr on the lesioned side was not altered by the intrastriatal grafts (Figs. 2 and 3).

Methamphetamine induced a similar pattern of Zif268 expression in the medial $\mathrm{CPu}$ to that of Fos in the three groups (control, lesion, graft) (Figs. 2 and 4). Regarding the GP and SNr, however, little Zif268 expression was observed on both sides in all three groups even after the methamphetamine administration (Figs. 4 and 5).

\section{DISCUSSION}

Constitutive levels of Zif268 were seen in the striatum, where very low levels of Fos were observed, con-
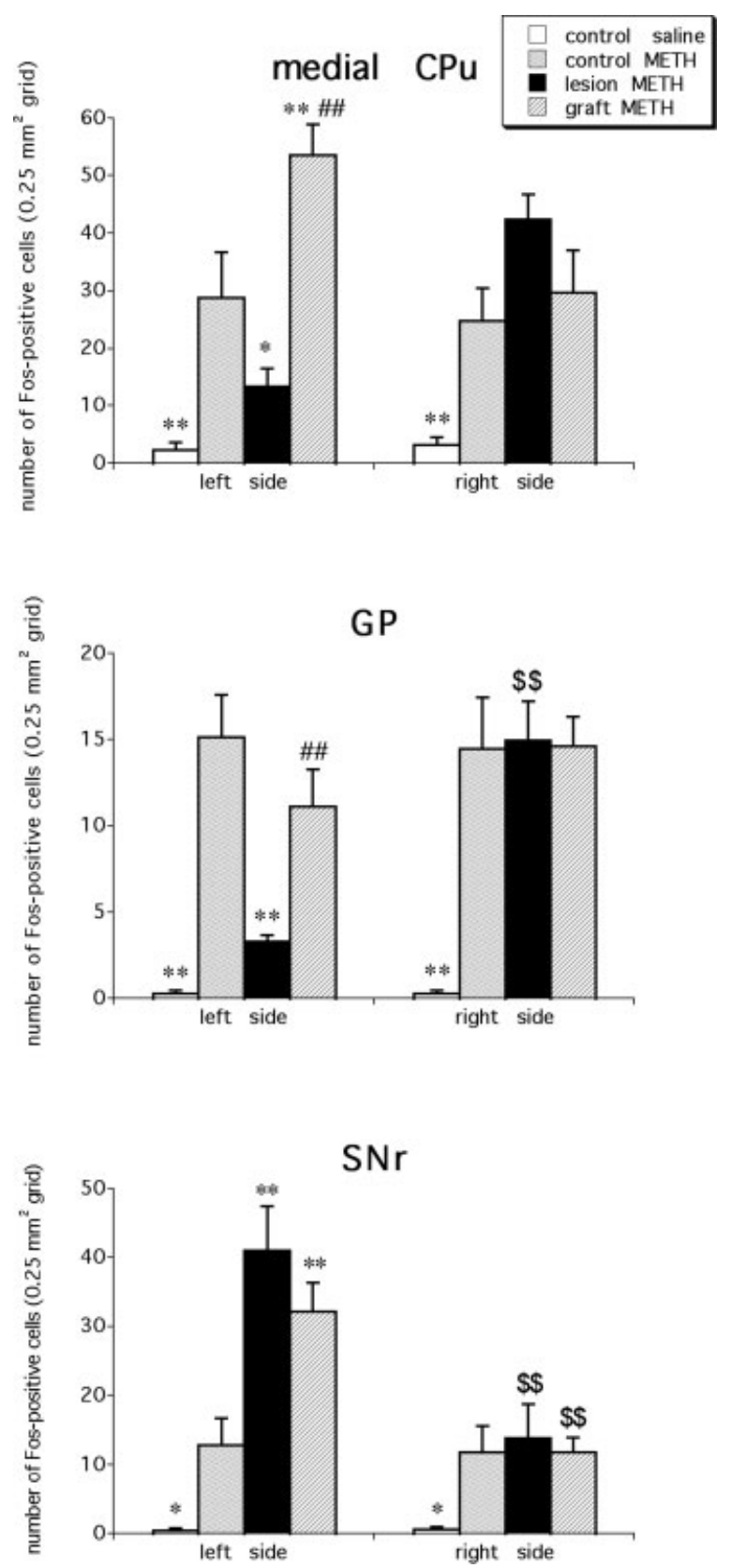

Fig. 3. Density of Fos-positive cells (number $/ 0.25 \mathrm{~mm}^{2}$ ) as detected within the medial CPu (top panel), GP (middle panel) and the $\mathrm{SNr}$ (bottom panel) in saline-treated controls $(n=6)$, methamphetamine $(3 \mathrm{mg} / \mathrm{kg}$, i.p.)-treated controls $(n=6)$, methamphetamine-treated lesioned $(n=6)$ and methamphetamine-treated grafted rats $(n=6)$. METH, methamphetamine. The results are the means \pm SEM. $* P<0.05, * * P<0.01$ in comparison to each corresponding value of the methamphetamine-treated control rats (twoway ANOVA followed by Newman-Keuls test). ${ }^{\# \#} P<0.01$ for the methamphetamine-treated graft group in comparison to each corresponding value of the methamphetamine-treated lesioned rats (twoway ANOVA followed by Newman-Keuls test). ${ }^{\$ \$} P<0.01$ in comparison to each value in the corresponding ipsilateral (left side) portion of the same group (two-way ANOVA followed by Dunnett's $t$-test).

sistent with that seen in previous studies (Ishida et al., 2000; MacGibbon et al., 1995). Constitutively expressed IEGs may perhaps be involved in control- 


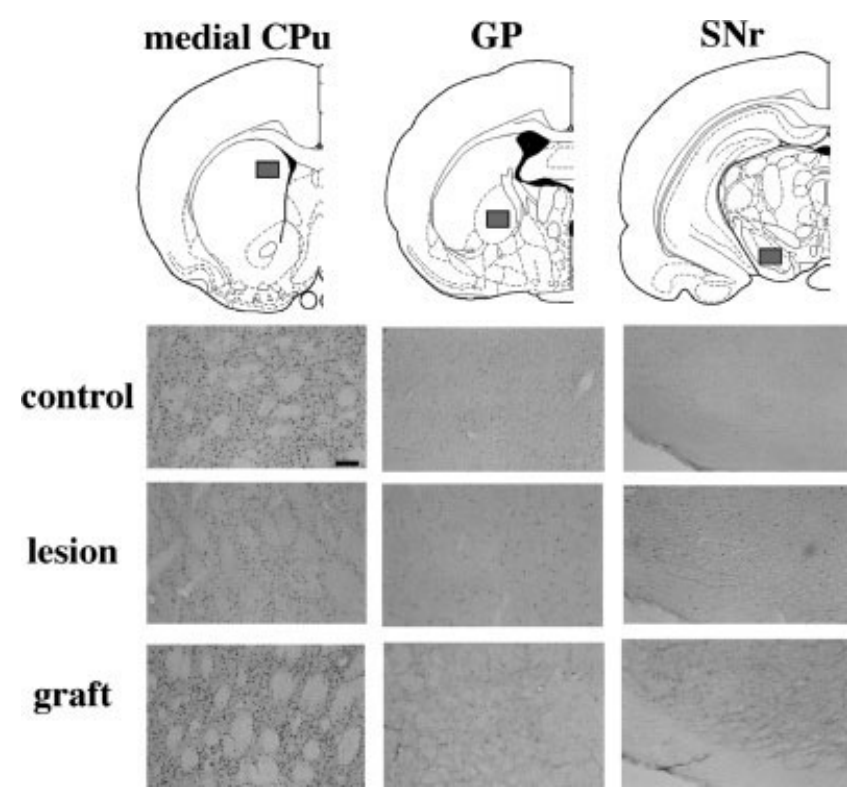

Fig. 4. Zif268 expression $2 \mathrm{~h}$ after methamphetamine $(3 \mathrm{mg} / \mathrm{kg}$, i.p.) administration in the basal ganglia nuclei of the control, the lesioned and the grafted rats ipsilateral to the lesion/graft (left side). $\mathrm{CPu}$, caudate putamen; GP, globus pallidus; SNr, substantia nigra pars reticulata. The box in the drawing indicates the location of areas where photomicrographs were taken. Scale bar $=100 \mu \mathrm{m}$.

ling housekeeping genes stimulated by tonic messengers, such as glutamate through NMDA receptors (Ishida et al., 2000). The genes activated basally may include those genes that sustain neuronal cell function and viability, while the novel messengers arriving at the cell surface, which rapidly and transiently activate IEGs, work to modulate the transcriptional activity of other genes that change the phenotype of the cell depending on the information carried by the messenger. Alternatively, perhaps the IEG proteins present basally are not active, and their activation requires post-translational modifications (phosphorylation, demethylation, etc.) (Seyfert et al., 1990). A previous report suggested that Zif268 may play a role in spontaneously maintaining the inhibitory output of GABAergic neurons in the striatum (Ishida et al., 2000).

Based on the results described previously (Ishida et al., 1996; Schmidt et al., 1983), it appears that an almost complete loss of the DA content is achieved in the denervated striatum in the 6-OHDA-treated rats in the present study. Previous cerebral dialysis and immunohistochemical studies have shown that basal and methamphetamine-induced DA release was recovered and that an abundance of tyrosine hydroxylase-immunopositive cells and fibers could be observed in the lesion-grafted striatum in the grafted rats in which methamphetamine-induced rotation was completely ameliorated similarly in the present study (Ishida et al., 1998a; Nishino et al., 1990).
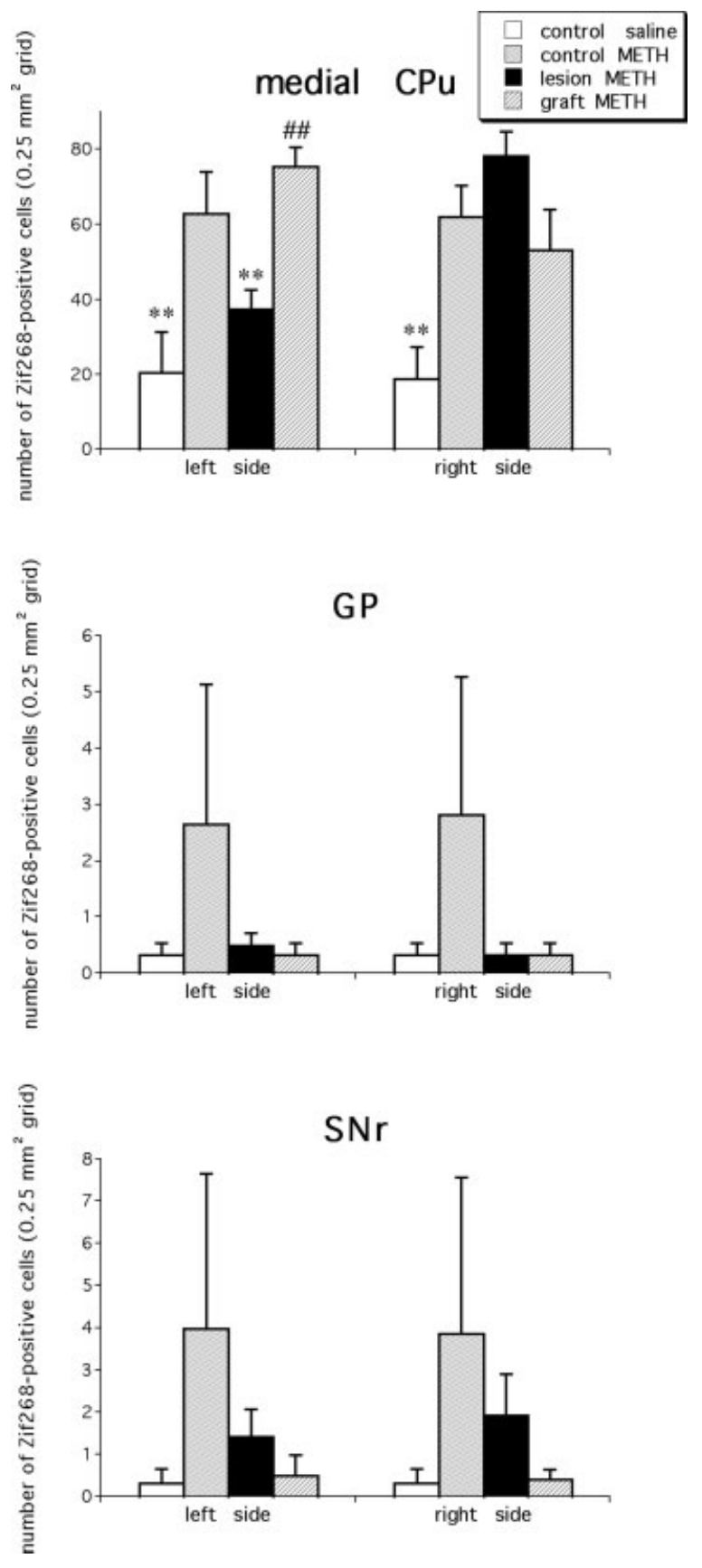

Fig. 5. Density of Zif268-positive cells (number/0.25 $\mathrm{mm}^{2}$ ) as detected within the medial $\mathrm{CPu}$ (top panel), GP (middle panel) and the $\mathrm{SNr}$ (bottom panel) in saline-treated controls $(n=6)$, methamphetamine $(3 \mathrm{mg} / \mathrm{kg}$, i.p.)-treated controls $(n=6)$, methamphetamine-treated lesioned $(n=6)$ and methamphetamine-treated grafted rats $(n=6)$. METH, methamphetamine. The results are the means \pm SEM. ${ }^{* *} P<0.01$ in comparison to each corresponding value of the methamphetamine-treated control rats (two-way ANOVA followed by Newman-Keuls test). ${ }^{\# \#} P<0.01$ for the methamphetamine-treated graft group in comparison to each corresponding value of the methamphetamine-treated lesioned rats (two-way ANOVA followed by Newman-Keuls test).

A large increase in Fos and Zif268 levels were observed in the striatum after methamphetamine administration, as observed in previous studies 
(Moratalla et al., 1992; Wang et al., 1994). Similar to the pattern of Fos activation, methamphetamineinduced Zif268 activation was lower in the lesioned striatum and higher (although, not significantly) in the lesion-grafted striatum in comparison to that in the control striatum. However, the drug-regulated expression of these two genes is not identical: the atypical antipsychotic drug clozapine induces zif268 but not c-fos in the caudate-putamen (Nguyen et al., 1992). The differential regulation of c-fos and zif268 has been reported in the dentate gyrus of the hippocampus after the high-frequency stimulation of the perforant path (Cole et al., 1989). The similarity in the distribution of inducible expression suggests that although these two IEGs may differ in their functions in quiescent neurons, they may have analogous or cooperative roles in neuronal responses to methamphetamine in the control, lesioned, or lesion-grafted striatum.

Similar to the results reported previously (Abrous et al., 1992; Cenci et al., 1992), the present study demonstrates that the stimulant effect of methamphetamine on Fos expression can be restored, and furthermore, the density of methamphetamineinduced FLI within the grafted striatum is larger than that observed within the normal striatum. Abrous et al. have suggested (1992) that the exaggerated pharmacological response following intrastriatal grafting of VM might be linked to an abnormal postsynaptic restitution of DA control over the activity of target striatal neurons. Although the lesion-induced motor imbalance was ameliorated completely in the grafted rats, the intrastriatal grafts had little influence on the methamphetamine-induced hyperexpression of FLI in the SNr on the lesioned side. Therefore, the hyperexpression of nigral FLI could be induced independently of the tuning behavior following methamphetamine administration.

The 6-OHDA lesion can lead to the depletion of DA, not only in the striatum but also in the prefrontal cortex, the subthalamic nucleus, and various other limbic targets, which may induce postsynaptic alterations in the DA receptor number and in the sensitivity of various receptor-linked biochemical events in these areas (Campbell et al., 1985; Joyce, 1991; Mishra et al., 1980). The postsynaptic alterations remaining in the denervated areas except for the DAreinnervated striatum might explain the failure of intrastriatal grafts to exert significant effects on methamphetamine-induced Fos activation in the $\mathrm{SNr}$ on the lesioned side. It is suggested that the FLIs in the two discrete sites, medial $\mathrm{CPu}$ and $\mathrm{SNr}$, are activated independently by different mechanisms, and furthermore, different neuronal pathways are involved in the methamphetamine-induced rotation and Fos expression in the SNr of 6-OHDA rats.

Although the mechanism by which methamphetamine induces pallidal Fos is unclear, one possibility is that methamphetamine reduces striopallidal transmission through increased DA $\mathrm{D}_{2}$ receptor activation. This notion is supported in a study by Floran et al. (1997) which showed that methamphetamine or the $\mathrm{D}_{2}$ agonist, quinpirole, inhibits the release of GABA in the GP of the rat. Also, Black et al. (1997) used positron emission tomography (PET) in the baboon to demonstrate that cerebral blood flow to the GP is reduced significantly after the intravenous administration of a $\mathrm{D}_{2}$-selective agonist.

In the 6-OHDA rats, a significant difference in the methamphetamine-induced FLI between the lesioned and the intact striata was present also in GP. The side-to-side difference in GP seen in the 6-OHDA rats was no longer present in the grafted animals. As Cenci et al. reported previously (1992); fetal VM transplants normalize DA receptor-mediated function in a primary target of the striatal output neurons, the GP, as well as in the 6-OHDA-lesioned striatum.

In contrast to the striatum, both of the GP and $\mathrm{SNr}$ showed little Zif268 activation following methamphetamine challenge in rats of the three groups (control, lesion, graft). It is noteworthy to mention that Zif268 immunoreactivity was not increased in parallel with Fos following methamphetamine administration, indicating that the specific pattern of IEGs activation upon stimulation of dopaminergic neurons seems to be maintained in the basal ganglia.

In conclusion, the differential expression of Fos and Zif268 was observed among three regions (medial $\mathrm{CPu}, \mathrm{GP}, \mathrm{SNr}$ ) of the nigrostriatal system following methamphetamine in 6-OHDA-treated hemiparkinsonian rats, thus suggesting the presence of both genespecific and region-specific functions of Fos and Zif268 in the basal ganglia nuclei. Further studies are necessary to elucidate CNS functions of the IEGs in diverse ways.

\section{ACKNOWLEDGMENT}

The authors thank Ms. Fumiko Tsuda for her excellent technical assistance.

\section{REFERENCES}

Abrous DN, Torres EM, Annett LE, Reading PJ, Dunnett SB. 1992. Intrastriatal dopamine-rich grafts induce a hyperexpression of Fos protein when challenged with amphetamine. Exp Brain Res 91:181-190.

Bhat RV, Cole AJ, Baraban JM. 1992. Role of monoamine systems in activation of zif268 by cocaine. J Psychiatry Neurosci 17:94102.

Björklund A, Dunnett SB. 1992. Neural transplantation in adult rats. In: Dunnett SB, Björklund A, editors. Neural transplantation. A practical approach. New York: Oxford University Press. p $57-78$.

Black KJ, Gado MH, Perlmutter JS. 1997. PET measurement of dopamine D2 receptor-mediated changes in striatopallidal function. J Neurosci 17:3168-3177.

Campbell GA, Eckardt MJ, Weight FF. 1985. Dopaminergic mechanisms in subthalamic nucleus of rat: Analysis using horseradish peroxydase and microiontophoresis. Brain Res 333:261-270. 
Cenci MA, Kalén P, Mandel RJ, Wictorin K, Björklund A. 1992. Dopaminergic transplants normalize amphetamine- and apomorphine-induced Fos expression in the 6-hydroxydopamine-lesioned striatum. Neuroscience 46:943-957.

Cole AJ, Saffen DW, Baraban JM, Worley PF. 1989. Rapid increase of an immediately early gene messenger RNA in hippocampal neurons by synaptic NMDA receptor activation. Nature 340:474476 .

Dragunow M, Currie RW, Faull RLM, Robertson HA, Jansen K. 1989. Immediate-early genes, kindling and long-term potentiation. Neurosci Biobehav Rev 13:301-313.

Dunnett SB, Björklund A. 1992. Staging and dissection of rat embryos. In: Dunnett SB, Björklund A, editors. Neural transplantation. A practical approach. New York: Oxford University Press. p $1-19$.

Floran B, Floran L, Sierra A, Aceves J. 1997. D2 receptor-mediated inhibition of GABA release by endogenous dopamine in the rat globus pallidus. Neurosci Lett 237:1-4.

Hebb MO, Robertson HA. 1997. Coordinate suppression of striatal $n g f i-a$ and c-fos produces locomotor asymmetry and up-regulation of IEGs in the globus pallidus. Mol Brain Res 48:97-106.

Hebb MO, Robertson HA. 1999. Motor effects and mapping of cerebral alterations in animal models of Parkinson's and Huntington's diseases. J Comp Neurol 410:99-114

Ishida Y, Hashiguchi H, Todaka K, Kuwahara I, Mitsuyama Y. 1996. Dopaminergic transplants alter in vivo activity of tryptophan hydroxylase in the striatum in a rat model of Parkinson's disease. Neurosci Lett 210:75-78.

Ishida Y, Hashiguchi H, Todaka K, Kuwahara I, Ishizuka Y, Nakane H, Uchimura D, Nishimori T, Mitsuyama Y. 1998a. Serotonergic activity in the rat striatum after intrastriatal transplantation of fetal nigra as measured by microdialysis. Brain Res 788:207214.

Ishida Y, Todaka K, Kuwahara I, Nakane H, Ishizuka Y, Nishimori T, Mitsuyama Y. 1998b. Methamphetamine-induced Fos expression in the substantia nigra pars reticulata in rats with a unilateral 6-OHDA lesion of the nigrostriatal fibers. Neurosci Res 30:355-360.

Ishida Y, Hashiguchi H, Ishizuka Y, Todaka K, Kuwahara I, Mitsuyama Y, Nishimori T. 2000. Basal expression of c-Fos and Zif268 in the rat basal ganglia: Immunohistochemical characterization of striatal Zif268-positive neurons. Eur J Neurosci 12:771775.

Joyce JN. 1991. Differential response of striatal dopamine and muscarinic cholinergic receptor subtypes to the loss of dopamine. I. Effects of intranigral or intracerebroventricular 6-hydroxydopamine lesions of the mesostriatal dopamine system. Exp Neurol 113:261-276

Kerpolla TK, Curran T. 1991. Fos-Jun heterodimers and jun homodimers bend DNA in opposite directions: Implications for transcription factor cooperatively. Cell 66:317-326.

König JFR, Klippel RA. 1963. The rat brain. A stereotaxic atlas of the forebrain and lower parts of the brain stem. Baltimore: Williams and Wilkins.

Lemaire P, Revelant O, Bravo R, Charnay P. 1988. Two mouse genes encoding potential transcriptional factors with identical DNA- binding domains are activated by growth factors in cultured cell. Proc Natl Acad Sci USA 85:4591-4694.

Lemaire P, Vesque C, Schmitt J, Stunnenberg H, Frank R, Charnay P. 1990. The serum-inducible mouse gene krox 24 encodes a sequence-specific transcription activator. Mol Cell Biol 10:34563467.

MacGibbon GA, Lawlor PA, Hughes P, Young D, Dragunow M. 1995 Differential expression of inducible transcription factors in basal ganglia neurons. Mol Brain Res 34:294-302.

Mishra RK, Marshall AM, Varmuza SL. 1980. Supersensitivity in rat caudate nucleus: Effects of 6-hydroxydopamine on the time course of dopamine receptor and cyclic AMP changes. Brain Res 200:47-57.

Moratalla R, Robertson HA, Graybiel AM. 1992. Dynamic regulation of NGFI-A (zif268, egr1) gene expression in the striatum. J Neurosci 12:2609-2622.

Morgan JI, Curran T. 1991. Stimulus-transcription coupling in the nervous system: involvement of the inducible proto-oncogenes fos and jun. Annu Rev Neurosci 14:421-451.

Nguyen TV, Kosofsky BE, Birnbaum R, Cohen BM, Hyman SE. 1992. Differential expression of c-Fos and Zif268 in rat striatum after haloperidol, clozapine, and amphetamine. Proc Natl Acad Sci USA 89:4270-4274.

Nishino H, Hashitani T, Kumazaki M, Sato H, Furuyama F, Isobe Y, Watari N, Kanai M, Shiosaka S. 1990. Long-term survival of grafted cells, dopamine synthesis/release, synaptic connections, and functional recovery after transplantation of fetal nigral cells in rats with unilateral 6-OHDA lesions in the nigrostriatal dopamine pathway. Brain Res 534:83-93.

Robertson HA, Peterson MR, Murphy K, Robertson GS. 1989. D D $_{1}$ dopamine receptor agonists selectively activate striatal c-fos independent of rotational behaviour. Brain Res 503:346-349.

Schmidt RH, Björklund A, Stenevi U, Dunnett SB, Gage FH. 1983. Intracerebral grafting of neuronal cell suspensions. III. Activity of intrastriatal nigral suspension implants as assessed by measurements of dopamine synthesis and metabolism. Acta Physiol Scand Suppl 522:19-28.

Seyfert VL, McMahon SB, Glenn WD, Yellen AJ, Sukhatme VP, Cao X, Monroe JG. 1990. Methylation of an immediate-early inducible gene as a mechanism for B cell tolerance induction. Science 250: 797-799.

Sheng M, Greenberg ME. 1990. The regulation and function of c-fos and other immediate early genes in the nervous system. Neuron 4:477-485.

Umino A, Nishikawa T, Takahashi K. 1995. Methamphetamineinduced nuclear c-Fos in rat brain regions. Neurochem Int 26:8590 .

Ungerstedt U. 1971. Striatal dopamine release after amphetamine or nerve degeneration revealed by rotational behavior. Acta Physiol Scand 367:51-68.

Wang JQ, Daunais JB, McGinty JF. 1994. NMDA receptors mediate amphetamine-induced upregulation of zif/268 and preprodynorphin mRNA expression in rat striatum. Synapse 18:343-353.

Wirtshafter D, Asin KE. 1999. Unilateral dopamine depletion paradoxically enhances amphetamine-induced Fos expression in basal ganglia output structures. Brain Res 824:81-88. 